\title{
Kondisi Ekologi Mangrove Di Perairan Guraping, Kota Tidore Kepulauan Provinsi Maluku Utara
}

\section{Mangrove Ecological Conditions in Guraping Waters, Tidore City, North Maluku Province}

\author{
${ }^{1}$ Abdul Motalib Angkotasan dan Husain Marasabessi ${ }^{2}$ \\ ${ }^{1}$ Program Studi Ilmu Kelautan, FPIK, Universitas Khairun, Ternate \\ ${ }^{2}$ Kehutanan Universitas Patimura Ambon \\ E-mail:abd.motalibangkotasan@gmail.com
}

\begin{abstract}
ABSTRAK
Ekosistem mangrove merupakan ekosistem utama wilayah pesisir dan laut, ekosistem ini memiliki peran dan fungsi yang sangat besar dalam menyediakan produk perikanan dan kelautan. Menjadi penyuplai flasmanutfa bagi kebutuhan hidup manusia. Perairan Guraping memiliki kawasan ekosistem mangrove yang baik dan dapat dikembangkan menjadi kawasan ekowisata mangrove. Dalam upaya pengembangan itu, dibutuhkan adanya data dan informasi tentang kondisi ekosistem mangrove baik hutan mangrove maupun biota asosiasi dan kondisi ekologi serta aspek hidrooseanografinya. Dengan demikian maka penelitian tentang infentarisasi jenis mangrove di perairan guraping sangat penting dilakukan. Tujaun dari penelitian ini adalah untuk menginventarsir jumlah jenis mangrove yang ada di Perairan Guraping, untuk menganalisis kondisi ekologi ekosistem mangrove di perairan guraping. manfaat yang diaharapkan adalah diperolehnya data dan informasi tentang kondisi ekosistem mangrove di perairan guraping baik jumlah jenis maupun kondisi ekologinya. Pengambilan data dalam penelitian ini menggunakan metode line intercept transect (LIT). Data yang diperoleh kemudian dianalisis untuk mengetahui kondisi ekologisnya. Analisis yang dilakukan adalah analisis tingkat kepadatan realitif, persentase tutupan realitif, dominansi realtif dan nilai penting. Berdasarkan hasil analisis data ditemukan adanya 16 jenis tumbuhan mangrove yang terdiri dari 10 jenis mangrove sejati dan 6 jenis tumbuhan yang berasosiasi dengan ekosistem mangrove.Ekosistem manrove di Perairan Guraping didominasi oleh mangrove jenis Rhizhophora sp dengan spesies yang dominan ditemukan adalah spesies Rhizhophora apiculata dan Rhizhophora mucronata. Kedua spesies ini ditemukan di semua lintasan pengamtan. Terdapat pula jenis jenis mangrove yang lain yakni Sonaratia alba, Bruguiera gymnoricha, Avicenia marina, Avicenia alba, Aegyceras floridium, Ceriops decandra, Xilacarpus granatum dan Nypa. Selain itu ditemukan pula beberapa jenis tumbuhan tumbuhan yang berasosiasi dengan ekosistem mangrove yakni jenis Pandanus spp, paku-pakuan, kayu baru, pohon aren, Ipomea pes-caprae dan pohon sagu. Berdasarkan hasil analisis ditemukan bahwa nilai indeks penting ekosistemn mangrove di perairan Guraping sebesar 16 dari jenis avicenia marina mangrove jenis Rhizhophora apiculata dominan ditemukan di lokasi penelitian dengan nilai indkes dominansi sebesar. Simpulan yang dapat diambil adalah, mangrove jenis Rhizhophora apiculata dominan ditemukan di lokasi penelitian dan meiliki nilai indeks keanekaragaman yang tetinggi rata-rata sebesar 0.36 .
\end{abstract}

Kata kunci : Ekologi, mangrove, guraping, Rhizhophora apiculata

\section{ABSTRACK}


Mangrove ecosystems are the main ecosystems of coastal and marine areas, these ecosystems have a very large role and function in providing fisheries and marine products. Being a supplier of physical for the needs of human life. But today, these three ecosystems are experiencing significant degradation. According to Dahuri (2001) every year coastal and marine ecosystems suffer approximately $20 \%$ damage. Guraping dance has a good mangrove ecosystem area and can be developed into a mangrove ecotourism area. In an effort to develop it, it is necessary to have data and information about the condition of the mangrove ecosystem both mangrove forests and biota associations and ecological conditions as well as the hydrooseanographic aspects. Thus, research on the identification of mangrove species in guraping waters is very important. The objective of this research is to inventory the number of mangrove species in the Guraping Waters, to analyze the ecological conditions of the mangrove ecosystem in the Guraping waters. the expected benefit is to obtain data and information about the condition of mangrove ecosystems in guraping waters both in number of species and their ecological conditions. Retrieval of data in this study using the line intercept transect (LIT) method. The data obtained are then analyzed to determine the ecological conditions. The analysis conducted is the analysis of the level of real density, percentage of real cover, real dominance and significance value. Based on the results of data analysis found 16 species of mangrove plants consisting of 10 species of true mangroves and 6 species of plants associated with mangrove ecosystems. Manrove ecosystems in Guraping waters are dominated by mangrove species of Rhizhophora sp. The dominant species found are species of Rhizhophora apiculata and Rhizhophora mucronata. Both of these species are found on all safety trajectories. There are also other types of mangroves namely Sonaratia alba, Bruguiera gymnoricha, Avicenia marina, Avicenia alba, Aegyceras floridium, Ceriops decandra, Xilacarpus granatum and Nypa. In addition, several types of plants associated with mangrove ecosystems were also found, namely Pandanus spp species, ferns, new wood, palm trees, Ipomea pes-caprae and sago trees. Based on the results of the analysis it was found that the important index value of mangrove ecosystems in Guraping waters was 16 of the avicenia marina type of mangrove species of Rhizhophora apiculata dominant found in the study location with a dominant index of magnitude of. The conclusion that can be taken is that the dominant species of Rhizhophora apiculata mangrove is found in the study location and has a high diversity index value of 0.36 .

Keyword : ecology, mangrove, Guraping, Rhizhophora apiculata

\section{Pendahuluan}


Ekosistem mangrove di Indonesia mengalami degradasi yang mengkhawatirkan, kurang lebih 25\% kawasan hutan mangrove yang terdegradasi setiap tahunnya (Dahuri, 2001). Kerusakan ini dipicu oleh bebagai aktivitas manusia diantaranya pembukaan tambak untuk areal budidaya didaerah manrgive, sediemntasi, pembukaan lahan di daratan. Menurut Dahuri ddk (2004) permasalahan utama tentang tekanan terhadap hitan mangrove bersumber dari keonginan manusia untuk mengkonversi area hutan mangrove menjadi areal pengembangan perumahan, kegiatan-kegiatan komersial, industry dan pertanian. Kegiatan lain yang menyebabkan kerusakan hutan mangrove cukup besar adalah pembukaan tambak-tambak untuk budidaya perairan. Oleh karena itu maka diperluakan langkah kongkrit dalam merumuskan skeanrio pengelolaan mangrove agar terhindar dari degradasi. Salah satu langkah utama adalah kajian tentang infentarisasi jenis mangrove sebagai upaya untuk mengumpulkan data dan informasi yang dibutuhkan dalam proses penyusunan skenario pengelolaan.

Maluku Utara memiliki kawasan ekosistem mangrove yang masih baik dan tersebar diberbagai wilayah di Maluku utara, salah satunya adalah kawasan ekosistem hutan mangrove di Perairan Guraping. Perarian ini memiliki kawasan ekosistem mangrove yang baik dan dapat dikembangkan menjadi kawasan ekowisata mangrove. Dalam upaya pengembangan itu, dibutuhkan adanya data dan informasi tentang kondisi ekosistem mangrove baik hutan mangrove maupun biota asosiasi dan kondisi ekologi serta aspek hidrooseanografinya. Dengan demikian maka penelitian tentang infentarisasi jenis mangrove di perairan guraping sangat penting dilakukan.

\section{Metodologi Penelitian \\ 2.1. Waktu dan tempat penelitian}

Penelitian ini dilaksanakan di Kawasan Ekosistem Perairan Guraping, Kecmatan Oba Utara, Kota Tidore Kepulauan, Provinsi Maluku Utara. Penelitian ini dilaksanakan delama 4 bulan mulai dari bulan April sampai Bulan Juli 2016. Peta lokasi penelitian dapat di lihat pada gambar dibawah ini :

\subsection{Teknik Pengambilan Data}

Metode yang dipakai dalam proses pengambilan data teridir dari metode pengambilan data mangrove, metode pengambilan data biota asosiasi dan metode pengambilan data lingkungan perairan. Pengambilan data mangrove menggunakan metode line intercept transect. Caranya adalah melatakn kuadran berukuran 50 x 50 m dengan cara merencatngkan tali rapia berukuran 50 x 50 meter dalam bentuk persegi empat. Setelah kaudran diletakan, langkah selanjutnya adalah mengamati jenis mangrove yang ada didalam kuadran lalu dicatat dalam table data. Didalan table data tersebut tercatat dengan jelas jenis mangrove, jumlah individu pohon, jumlah anakan, jumlah semaian dan diameter batang dari individu mangrove. Didialam kuadran 50 x 50 dibuatkan kuadran 10 x 10 untuk mendata jumlah anaknd an semaian yang terdapat didalamnya. 
JURNAL ILMU KELAUTAN KEPULAUAN, 2 (2) ;32-39, DESEMBER 2019

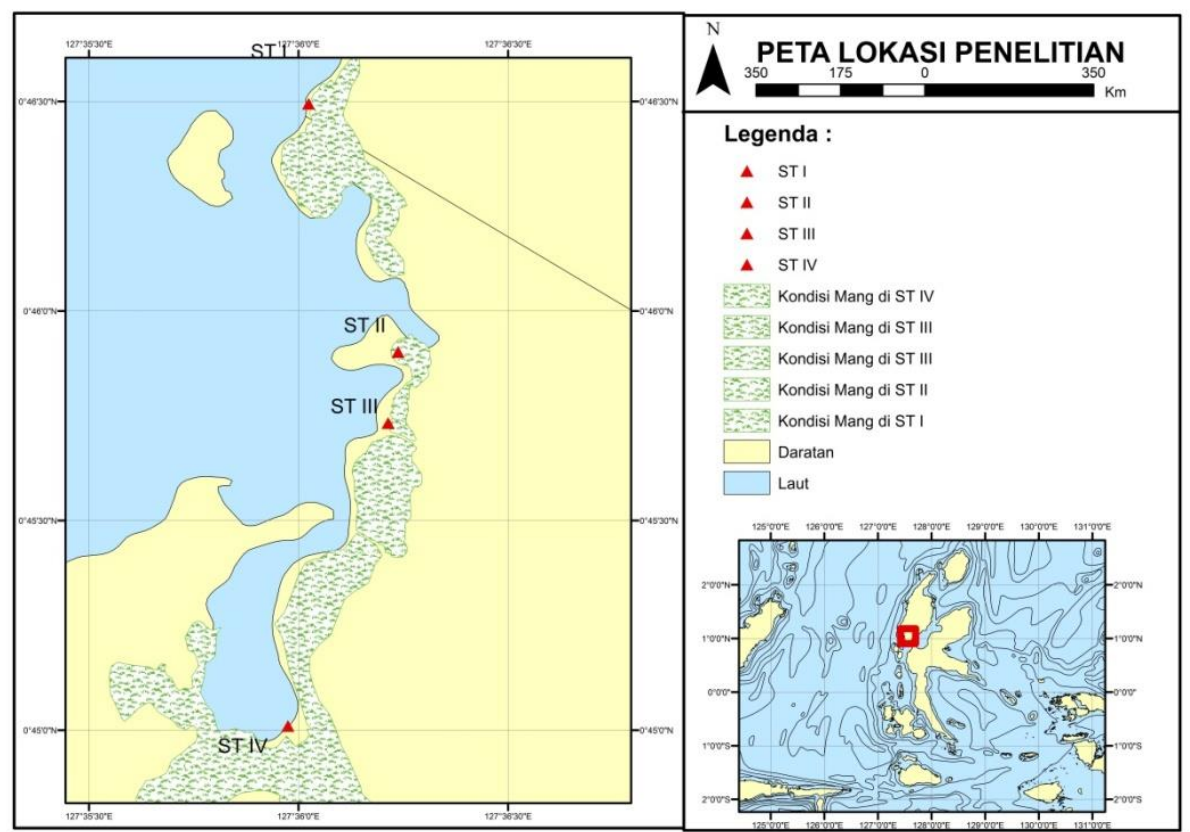

Gambar : Peta Lokasi Penelitian

\subsection{Teknik Analisis Data}

Metode analsisi data yang digunakan dalam penelitian ini terdiri dari dua metode yakni metode analsisi data kuantitatif dan kualitatif.

a. Metode analisis data kuantitatif

Metode analisis data kuantitatif digunakan dalam proses analisis kondisi ekologi ekosistem mangrove yakni analisis keanekaragaman, kerapatan, kerapatan nisbi, dominansi, dominasi relative, frekuensi, frekuensi relative dan nilai penting.

\section{Vegetasi :}

Rumus-rumus yang digunakan dalam perhitungan analisis vegetasi dengan metode garis berpetak (Mueller-Dombois dan Ellenberg, 1974; Cox, 1975; Michael, 1985; Soerianegara dan Indrawan, 1985) adalah:

$$
\begin{aligned}
\text { Kerapatan (batang/ha) } & =\frac{\text { Jumlah individu suatu jenis }}{\text { Luas seluruh petak }} \\
\text { Kerapatan Relatif }(\%) & =\frac{\text { Kerapatan suatu jenis }}{\text { Kerapatan seluruh jenis }} \times 100 \% \\
\text { Dominansi }\left(\mathrm{m}^{2} / \mathrm{ha}\right) & =\frac{\text { Basal area suatu jenis }}{\text { Luas seluruh petak }} \\
\text { Dominansi Relatif }(\%) & =\frac{\text { Dominansi suatu jenis }}{\text { Dominansi seluruh jenis }} \times 100 \%
\end{aligned}
$$


JURNAL ILMU KELAUTAN KEPULAUAN, 2 (2) ;32-39, DESEMBER 2019

$$
\begin{array}{ll}
\text { Frekuensi } & =\frac{\text { Jumlah petak terisi suatu jenis }}{\text { Jumlah seluruh petak }} \\
\text { Frekuensi Relatif }(\%) & =\frac{\text { Frekuensi suatu jenis }}{\text { Frekuensi seluruh jenis }} \times 100 \% \\
\text { Indeks Nilai Penting } & =\mathrm{KR}+\mathrm{FR}+\mathrm{DR}
\end{array}
$$

Khusus untuk tingkat semai dan tumbuhan bawah, Indeks Nilai Penting cukup dihitung berdasarkan rumus :

$$
\text { Indeks Nilai Penting } \quad=\mathrm{KR}+\mathrm{FR}
$$

Parameter kuantitatif yang juga dihitung adalah, Indeks Keanekaragaman Shannon-Wiener (Shannon Index of General Diversity), Indeks Keseragaman (Equitability Index) dan Indeks Kesamaan Komunitas (Index of Similarity). Untuk menghitung Indeks Keanekaragaman Shannon-Wiener digunakan rumus sebagai berikut (Magurran, 1988) :

Indeks Keanekaragaman $\left(H^{\prime}\right)=-\Sigma\left[p_{i} \cdot \ln p_{i}\right]$

$$
\mathrm{Pi}=\frac{n i}{N}
$$

dimana :

$$
\begin{aligned}
& \mathrm{H}^{\prime}=\text { Indeks Keanekaragaman Shannon (Shannon Index of General Diversity). } \\
& \mathrm{n}_{\mathrm{i}}=\text { Indeks Nilai Penting suatu jenis. } \\
& \mathrm{N}=\text { Jumlah Indeks Nilai Penting dari seluruh jenis. }
\end{aligned}
$$

b. Metode analisis data kualitatif

Metode analisis data kualitatif dengan teknik deskriptif digunakan untuk menganalisis hasik pengamatan observasi biota asosiasi dan data hasil pengukuran kondisi kualitas perairan.

\section{Hasil dan Pembahasan}

\subsection{Profil Ekosistem Mangrove di Peraian Guraping}

Ekosistem mangrove di Perairan Guraping didominasi oleh mangrove jenis Rhizhophora sp dengan spesies yang dominan ditemukan adalah spesies Rhizhophora apiculata dan Rhizhophora mucronata. Kedua spesies ini ditemukan di semua lintasan pengamtan. Terdapat pula jenis jenis mangrove yang lain yakni Sonaratia alba, Bruguiera gymnoricha, Avicenia marina, Avicenia alba, Aegyceras floridium, Ceriops decandra, Xilacarpus granatum dan Nypa. Selain itu ditemukan pula beberapa jenis tumbuhan tumbuhan yang berasosiasi dengan ekosistem mangrove yakni jenis Pandanus spp, paku-pakuan, kayu baru, pohon aren, Ipomea pes-caprae dan pohon sagu. 
JURNAL ILMU KELAUTAN KEPULAUAN, 2 (2) ;32-39, DESEMBER 2019



\subsection{Kondisi Ekologi Hutan Mangrove}

\section{a. Indeks Kerapatan, Dominansi dan Nilai Penting}

Hasil kondisi ekologis hutan mengrove pada perairan Guraping masih sangat baik. Berdasarkan hasil analisis data ditemukan nilai indeks dominansi tertinggi ditemukan pada jenis Rhizhophora apiculata sebesar 0.54, sedangkan nilai Frekuensi jenis tertinggi terdapat pada jenis yang sama dengan niali frekuensi relative jenis sebesar 0.009. indeks nilai penting tertinggi ditemukan pada jenis Rhizhophora aviculata, untuk lebih jelasnya dapat dilihat pada gamabr diagram dibawah ini :



Gambar 1. Nilai indeks ekologi ekosistem mangrove di Perairan Guraping

\section{b. Keanekaragaman Jenis}

Berdasrskan hasil analisis data ditemukan nilai keanekagaraman tertinggi ditemukan pada mangrove jenis Rhizhophora apiculata. Dari keemapat stasiun yang dianalisis, ditemukan nilai rata-rata dari analisis indeks keanekaragaman jenis Rhizhophora apiculata sebesar 0.36. jika dikaitkan dengan standar indeks keanekaragaman shanon winer, nilai keanekaragamannya masih rendah yakni $<1$. 


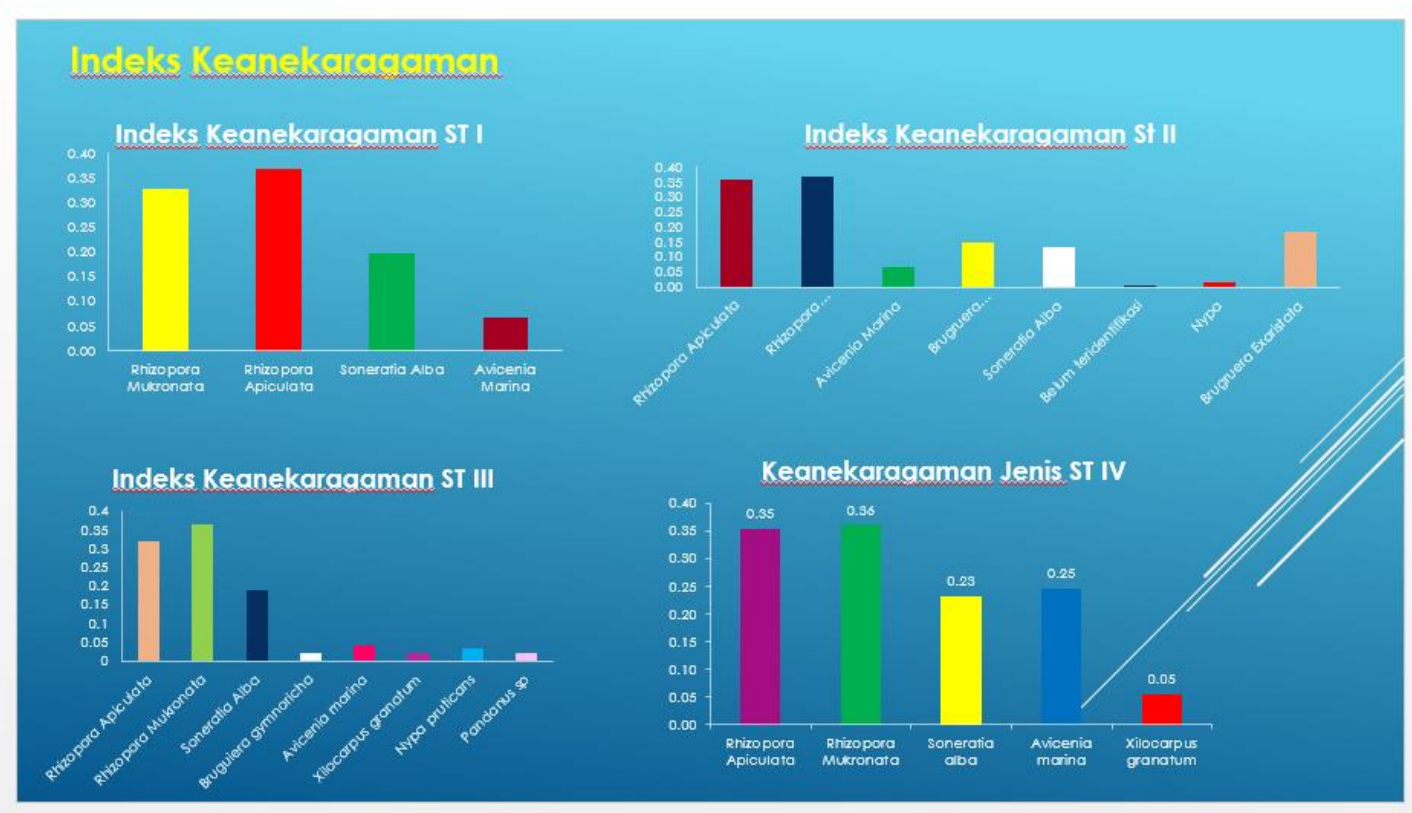

Gambar : Diagram Nilai Keanekaragaman Jenis Mangrove di Perairan Guraping

\subsection{Parameter Lingkunan di Perairan Guraping}

Pengukuran kondisi lingkungan menggunakan alat Water Quality Cecker, alat ini berfungsi mengukur kualitas air di suatu perairan. Parameter yang dapat di ukur xengan menggunakan alat ini adalah parameter suhu, salinitas, $\mathrm{pH}$ dan densitas. Hasil pengukuran kualitas air di perairan guraping menunjukan bahwa kondisi perairan ini kualitas airnya masih baik, dan masih sesuai dengan standar baku mutu lingkungan yang ditetapkan oleh Kementrian Lingkungan Hidup. Kondisi lingkungan perairan Guraping sangat baik, dan layak dikembangkan sebagai kawasan budidaya. Berdasarkan hasil pengukuran diperoleh data sebagaiamana yang tertera pada table dibawah ini :

Tabel 1. Kondisi Lingkungan di Perairan Guraping

\begin{tabular}{c|c|c|c|c|l}
\hline Stasiun & Suhu ( $\left.{ }^{\mathbf{0}} \mathbf{c}\right)$ & Salinitas (\%o) & $\mathbf{p H}$ & $\mathbf{p H}$ Soil & Substrat \\
\hline I & 29.7 & 35.8 & 9.22 & 7.5 & Berpasir \\
\hline II & 30 & 35.3 & 9.10 & 7.7 & Berlumpur \\
\hline III & 31.52 & 35.3 & 7.83 & 7.8 & Berlumpur \\
\hline IV & 30.5 & 35.5 & 7.94 & 7.3 & Berlumpur \\
\hline
\end{tabular}




\section{Kesimpulan}

Simpulan yang dapat diambl dari penelitian ini bahwa jenis mangrove yang dominan ditemukan di perairan Teluk Guraping adalah jenis Rhizhophora apiculata dan Rhizhophora mucronata. Jenis mangrove yang ditemukan di Perairan Guraping terdiri dari mangrove sejati dan mangrove ikutan, mangrove sejati terdiri dari jenis Rhizhophora mucronata, Rhizhophora apiculata, Sonaratia alba, Bruguiera gymnoricha, Avicenia marina, Xilkocarpus granatum dan Nypa frutican. Jenis biota asosiasi yang ditemukan di perairan guraping adalah ikan (Ikan kerapu, ikan julung, ikan beronang). Jenis non ikan (gastropoda, bivalvia). Substratnya didominasi oleh substrat berlumpur. Memiliki kualiatas air yang baik dengan kisaran suhu $29-$ $30^{\circ} \mathrm{C}$, dan salinitas $33-35 \%$.

\section{Daftar Pustaka}

Arief A. 2003. Hutan Mangrove Fungsi dan Manfaatnya.Kanisius. Yogyakarta.

Bengen, GD. 2002. Pengenalan dan Pengelolaan Ekosistem Mangrove. Pusat Kajian Sumberdaya Pesisir dan Lautan, Institut Pertanian Bogor.

Bengen, GD. 2003. Pedoman Teknis Pengenalan Pengelolaan kosistemMangrove. Pusat Kajian Sumberdaya Pesisir Dan Lautan (PKSPL)Institut PertanianBogor. Bogor.

Noor Yus Rusila,. M. Khazali dan IN. N. Suryadiputra. 2006. Panduan Pengenalan Mangrove di Indonesia. Bogor, Oktober 2006.

Ningsih S.S. 2008. Inventarisasi Hutan Mangrove Sebagai Bagian Dari Upaya Pengelolaan Wilayah Pesisir Kabupaten Deli Serdang. Tesis.SekolahPasca Sarjana UniversitasSumatera Utara. Medan.

Odum E. 1993. Dasar-Dasar Ekologi Gadjah Mada University Press: Yogyakarta

Wibisono M.S. 2010. Pengantar ilmu kelautan, Edisi 2. Penerbit Universitas Indonesia: Jakarta

Zainal R. 2014. Teknis Pemetaan Vegetasi Mangrove Dengan Aplikasi Sistem Informasi Geografis Desa Kaiyasa Kota Tidore Kepulawan. Ternate, April 2014. 